\title{
Investigation of a diode-pumped intracavity optical parametric oscillator in pulsed and continuous wave operation
}

Jensen, Ole Bjarlin; Skettrup, Torben; Balle-Petersen, O.; Bruun-Larsen, M.

Published in:

Proceedings on Conference on Lasers and Electro-Optics

Link to article, DOI:

10.1109/CLEO.2001.948141

Publication date:

2001

Document Version

Publisher's PDF, also known as Version of record

Link back to DTU Orbit

Citation (APA):

Jensen, O. B., Skettrup, T., Balle-Petersen, O., \& Bruun-Larsen, M. (2001). Investigation of a diode-pumped intracavity optical parametric oscillator in pulsed and continuous wave operation. In Proceedings on Conference on Lasers and Electro-Optics https://doi.org/10.1109/CLEO.2001.948141

\section{General rights}

Copyright and moral rights for the publications made accessible in the public portal are retained by the authors and/or other copyright owners and it is a condition of accessing publications that users recognise and abide by the legal requirements associated with these rights.

- Users may download and print one copy of any publication from the public portal for the purpose of private study or research.

- You may not further distribute the material or use it for any profit-making activity or commercial gain

- You may freely distribute the URL identifying the publication in the public portal 


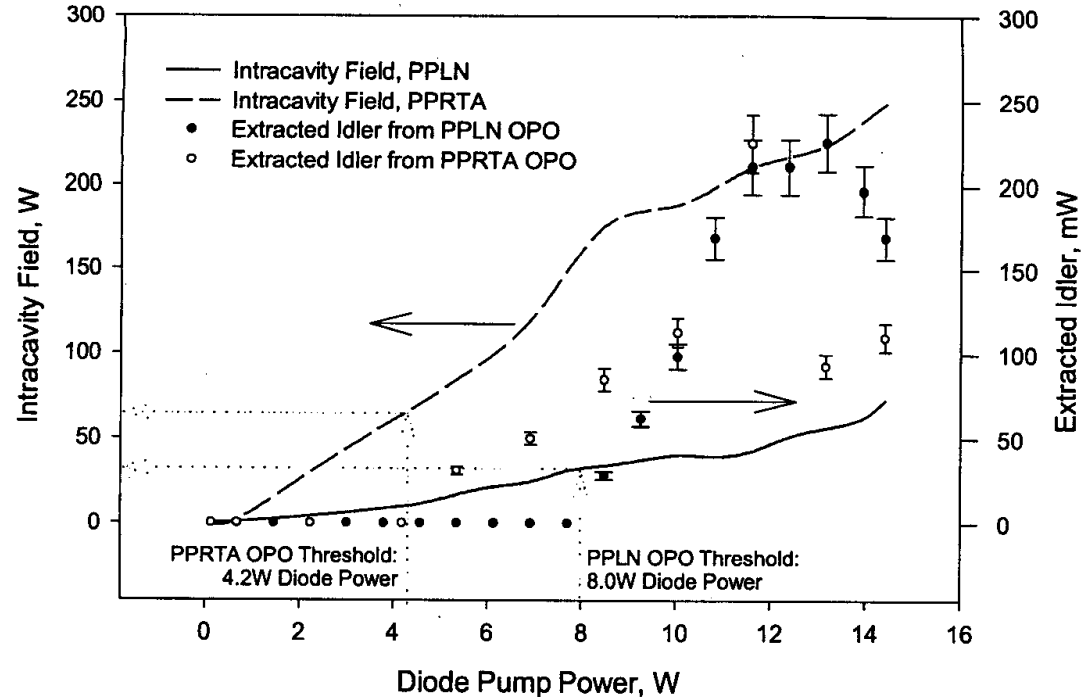

CThW4 Fig. 2. Extracted one-way idler output power and the one-way circulating intracavity pump-power at $1.064 \mu \mathrm{m}$ as a function of the external pump power from the diode laser for the case of PPLN and PPRTA

Figure 2 summarises performance of the two devices. The PPLN OPO has a lower threshold in terms of intracavity pump-field, namely $30 \mathrm{~W}$, compared to $65 \mathrm{~W}$ in the case of PPRTA; expected from its higher nonlinear coefficient. However, the external pump-power required to reach threshold is higher at $8 \mathrm{~W}$ in the case of PPLN compared to $4.2 \mathrm{~W}$ in the case of PPRTA as a result of the higher slope efficiency shown by the intracavity field in the latter material, ascribed to the greater immunity of PPRTA to thermal lensing and aperturing compared to PPLN. In both cases the output power in the idler wave is in the range $200-250 \mathrm{~mW}$ at external pump-powers of the order of $12 \mathrm{~W}$. (Unidirectional idler power, total generated power is twice this value). The spatial quality and temporal behaviour associated with the idler outputs are markedly different in the two cases. In PPRTA the idler mode is a stable, high spatial-quality mode close to TEM00, whereas in PPLN the spatial mode quality is both poor and unstable. In PPRTA the idler output from the OPO is true $\mathrm{CW}$ (intensity modulation below 5\%), whereas in PPLN trains of relaxation-oscillation pulses are continually triggered leading to severe and noisy intensity modulation.

Figure 3 shows the temperature tuning characteristics of the PPRTA. At $20^{\circ} \mathrm{C}$ (room temper- ature), the observed signal/idler wavelengths agree closely with those predicted by the Sellmeier relations of Fradkin \& Kashi. ${ }^{2}$

In PPLN we have.investigated cavity geometries which allow low threshold operation (intracavity fields around $6 \mathrm{~W}$ ), and enhanced idler outputs ( $350 \mathrm{~mW}$ at $12 \mathrm{~W}$ external purnping). We will report further on this and also on techniques for control of the relaxation oscillations that are still present in these improved geometries.

\section{Acknowledgments}

We would like to thank C.F. Rae for the provision of the PPRTA crystal and diode pump source, and $A$. Carleton for her useful assistance.

\section{References}

1. M. Ebrahimzadeh, G.A. Turnbull, T.J. Edwards, D.J.M. Stothard, I.D. Lindsay and M.H. Dunn, "Intracavity continuous-wave singly resonant optical parametric oscillators," Journal of the Optical Society of America B-Optical Physics 16, 1499-1511 (1999).

2. K. Fradkin-Kashi, A. Arie, P. Urenski and G. Rosenman, "Characterization of optical and nonlinear properties of periodically-poled $\mathrm{RbTiOAsO} 4$ in the mid-infrared range via difference-frequency generation," Applied Physics B-Lasers and Optics 71, 251-255 (2000).

3. D.L. Fenimore, K.L. Schepler, D. Zelmon, S. Kuck, U.B. Ramabadran, P. Von Richter and D. Small, "Rubidium titanyl arsenate difference-frequency generation and validation of new Sellmeier coefficients," Journal of the Optical Society of America B-Optical Physics 13, 1935 (1996).

4. H. Karlsson, F. Laurell, P. Henriksson and G. Arvidsson, "Frequency doubling in periodically poled RbTiOAsO4," Electronics Letters 32, 556-557 (1996).

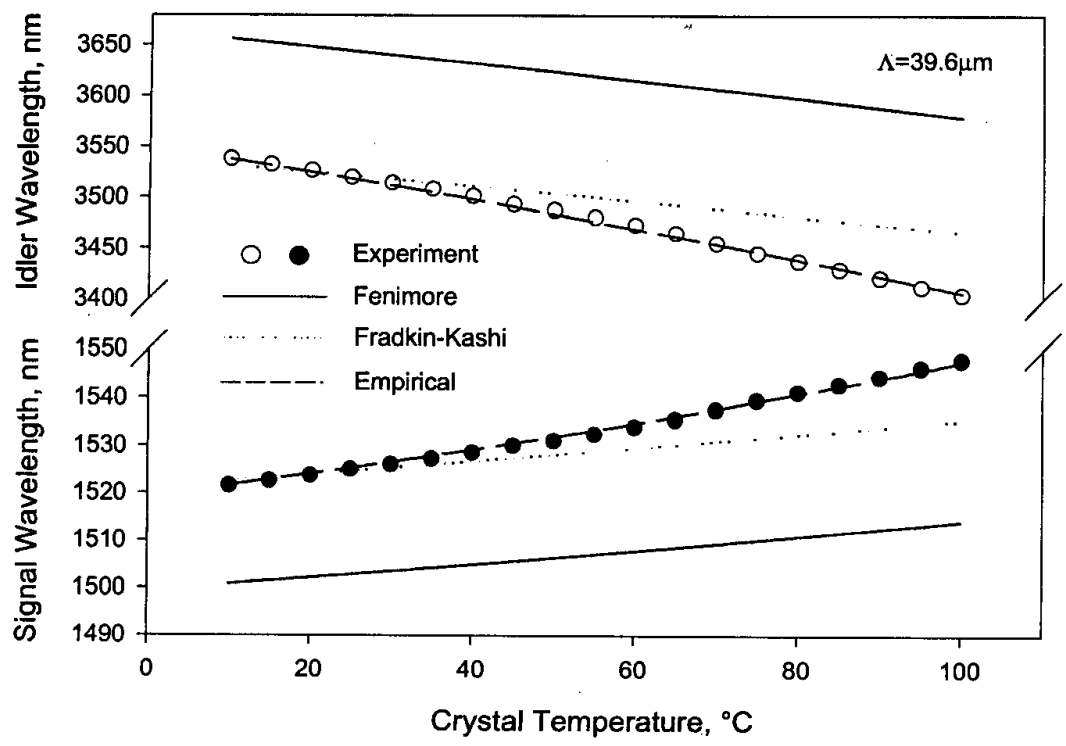

CThW4 Fig. 3. Experimental temperature tuning characteristics of PPRTA; upper trace (open circles) idler wave, lower trace (filled circles) signal wave. Calculated tuning characteristics based on Fradkin-Kashi ${ }^{2}$ and Fenimore ${ }^{3}$ are shown by dotted and solid lines respectively. In both cases, the temperature tuning characteristics were deduced using the (dn/dT) data of Karlsson. ${ }^{4}$
CThW5

$5: 45 \mathrm{pm}$

Investigation of a diode-pumped intracavity optical parametric oscillator in pulsed and continuous wave operation

O.B. Jensen, T. Skettrup, O. Balle-Petersen, ${ }^{*}$ M. Bruun-Larsen, ${ }^{*}$ Department of Physics, The Technical University of Denmark DK-2800 Lyngby; E-mail: ole.jensen@fysik.dtu.dk; ${ }^{*} A S A H$ Medico A/S, Valseholmen 11-13, DK-2650 Hvidovre, Denmark.

$\mathrm{Cw}$ and pulsed compact tuneable laser sources in the infrared have widespread scientific, medical and industrial applications. Such a laser source can be obtained by use of a diode-pumped intracavity optical parametric oscillator (IOPO)

Several investigations in this field have been published. ${ }^{1,2}$ Here we report on a IOPO based on a Yb:YAG laser incorporating a periodically poled $\mathrm{LiNbO}_{3}$ (PPLN) crystal inside the laser cavity to take advantage of the high circulating intracavity field. The Yb:YAG crystal is pumped by a reliable $940 \mathrm{~nm}$ fibre-coupled diode laser. The IOPO consists of a Yb:YAG crystal coated for $\mathrm{HR}$ at $1030 \mathrm{~nm}$, an intracavity lens to generate a beam waist in the PPLN crystal, a dichroic mirror to separate the laser and signal fields and two end mirrors as shown in Fig. 1.

The $30 \mathrm{~mm}$ long AR-coated PPLN crystal 


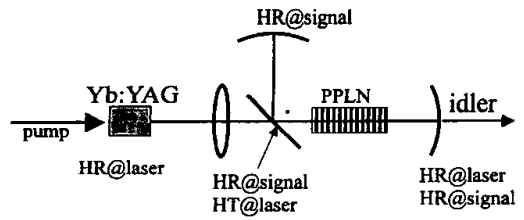

CThW5 Fig. 1. Schematic drawing of the IOPO.

contains 14 gratings with periods of $25.9 \mu \mathrm{m}$ to $29.5 \mu \mathrm{m}$. OPO operation have been obtained in gratings with periods of $25.9 \mu \mathrm{m}$ to $27.4 \mu \mathrm{m}$ corresponding to signal wavelengths in the range $1340-1410 \mathrm{~nm}$ and idler wavelengths in the range $3800-4450 \mathrm{~nm}$. The output power decreased with increasing idler wavelength due to absorption in the PPLN crystal. The signal output was coupled out of one of the two OPO end mirrors.

The output from the IOPO in $\mathrm{cw}$ and pulsed at $2 \mathrm{kHz}$ repetition rate can be seen in Fig. 2. In cw operation the expected clamping of the laser field is evident, whereas this does not occur in pulsed operation. The high threshold of the $\mathrm{cw}$ IOPO of approximately $20 \mathrm{~W}$ is attributed to losses in the IOPO, especially in the AR-coatings of the PPLN and from absorption in the PPLN.

The dynamics of the IOPO was investigated using fast photodiodes monitoring the laser and signal output. The dynamic behaviour is very different from the dynamic behaviour of the laser itself. The relaxation oscillations of the laser occurs at approximately $90 \mathrm{kHz}$, while the relaxation oscillations of the IOPO occur in the $\mathrm{MHz}$ range. This behaviour which is due to coupling between the non-linear OPO equations and the laser equations is in good agreement with the theory of Turnbull et al. ${ }^{3}$

1. M. Ebrahimzadeh, G.A. Turnbull, T.J. Edwards, D.J.M. Stothard, I.D. Lindsay, M.H. Dunn, J. Opt. Soc. Am. B., 16, 9, 1499-1511, (1999).

2. D.J.M. Stothard, M. Ebrahimzadeh, M.H. Dunn, Opt. Lett., 23, 24, 1895-1897, (1998).

3. G.A. Turnbull, D.J.M. Stothard, M. Ebrahimzadeh, M.H. Dunn, IEEE J. Quantum Electron., 35, 11, 1666-1672, (1999).
CThW6

6:00 pm

Dual-cavity DROPO_An ideal singte-mode source for non linear spectroscopy.

I. Ribet, C. Ventalon, C. Drag, M. Lefebvre, E. Rosencher, Office National d'Etudes et de Recherches Aérospatiales, B.P. 72-92322 Châtillon Cedex-France

With the appearance of periodically poled crystals, tremendous developments were recently obtained in the field of continuous-wave (cw) optical parametric oscillators. However, the low power delivered by $\mathrm{cw}$ sources is not appropriate to address the problems of non linear spectroscopy and open air pollutant species detection. Pulsed OPOs seem to be a good alternative for such applications since high output power can be delivered over a large domain of wavelengths from rugged and compact devices. Nonetheless, the broad spectral bandwidth of nanosecond-duration pulsed OPO remains a serious drawback for spectroscopic purposes. Thereby alternatives were proposed to achieve single-mode output. On the one hand, singlemode output has been demonstrated by use of the injection seeding technique despite of a restricted tuning range of the OPO to the seeder source. ${ }^{1}$ On the other hand, the insertion of filtering elements inside the cavity ${ }^{2}$ provides singlemode operation but important losses are introduced, increasing dramatically the threshold of oscillation.

In this paper, we propose a new alternative, based on a dual-cavity doubly resonant $\mathrm{OPO}^{3}$ Figures $1 \mathrm{a}$ and $1 \mathrm{~b}$ present two cavities that we tested in our lab. Figure $1 \mathrm{c}$ illustrates the principle of mode selection operated in these devices by use of a Giordmaine and Miller diagram : if a signal and an idler modes overlap perfectly, the energy conservation condition is fulfilled and those pairs of modes which are in exact coincidence are emitted. Practically, imperfect mode overlap can also lead to oscillation yielding to the well-known cluster behavior of single-cavity DROPOs. As we demonstrate here, using two separate cavities allows us to prevent oscillation with imperfect mode overlap. Hence, if only one exact coincidence lies within the gain bandwidth, the output will be single-mode. We thus capitalize on two advantages offered by the same double

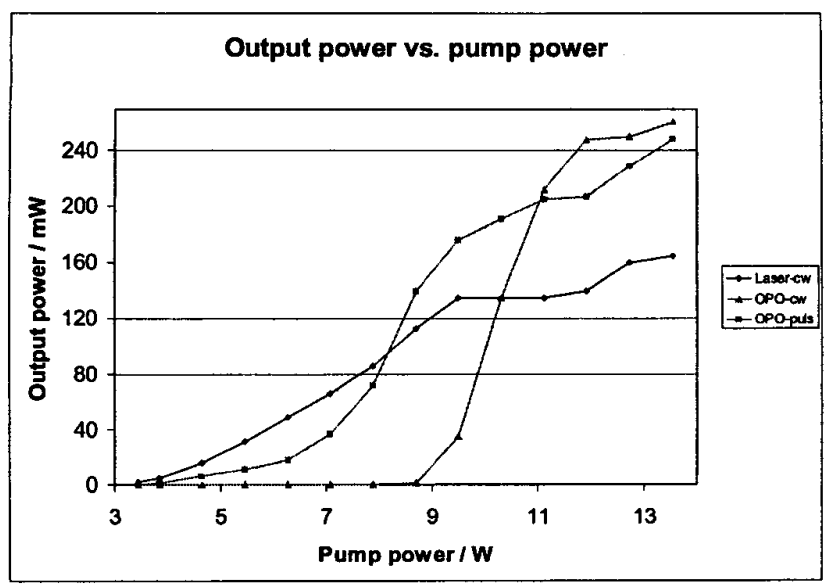

CThW5 Fig. 2. Output power from the IOPO in $\mathrm{cw}$ and pulsed operation.

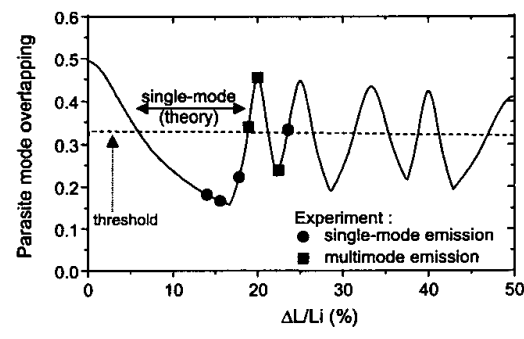

CThW6 Fig. 2. Overlap area as a function of the difference in length of the signal and idler cavities. Calculation corresponds to the L-shaped cavity OPO (gain bandwidth : $2.5 \mathrm{~cm}^{-1}$; signal and idler cavity finesses are 50 and 7 respectively). 